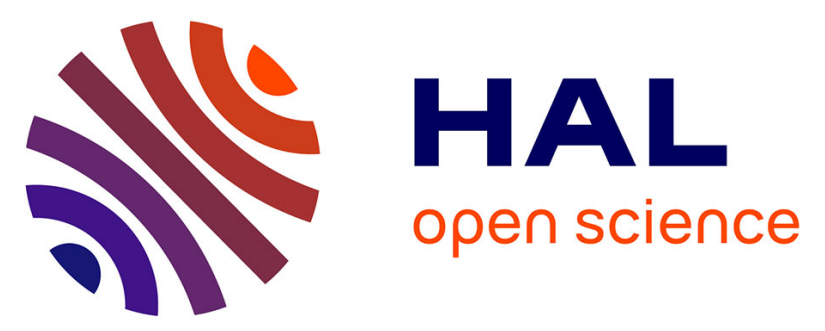

\title{
Two new eyeless mite species from western provinces of Iran: Stigmaeus ladanae n. sp. and Stigmaeus nasrinae n. sp. (Acari: Stigmaeidae)
}

A. Nazari, M. Khanjani, K. Kamali

\section{- To cite this version:}

A. Nazari, M. Khanjani, K. Kamali. Two new eyeless mite species from western provinces of Iran: Stigmaeus ladanae n. sp. and Stigmaeus nasrinae n. sp. (Acari: Stigmaeidae). Acarologia, 2012, 52 (2), pp.173-181. 10.1051/acarologia/20122047 . hal-01567032

\section{HAL Id: hal-01567032 \\ https://hal.science/hal-01567032}

Submitted on 21 Jul 2017

HAL is a multi-disciplinary open access archive for the deposit and dissemination of scientific research documents, whether they are published or not. The documents may come from teaching and research institutions in France or abroad, or from public or private research centers.
L'archive ouverte pluridisciplinaire HAL, est destinée au dépôt et à la diffusion de documents scientifiques de niveau recherche, publiés ou non, émanant des établissements d'enseignement et de recherche français ou étrangers, des laboratoires publics ou privés.

\section{(ㅇ)(1) $\$$}

Distributed under a Creative Commons Attribution - NonCommercial - NoDerivatives| 4.0 


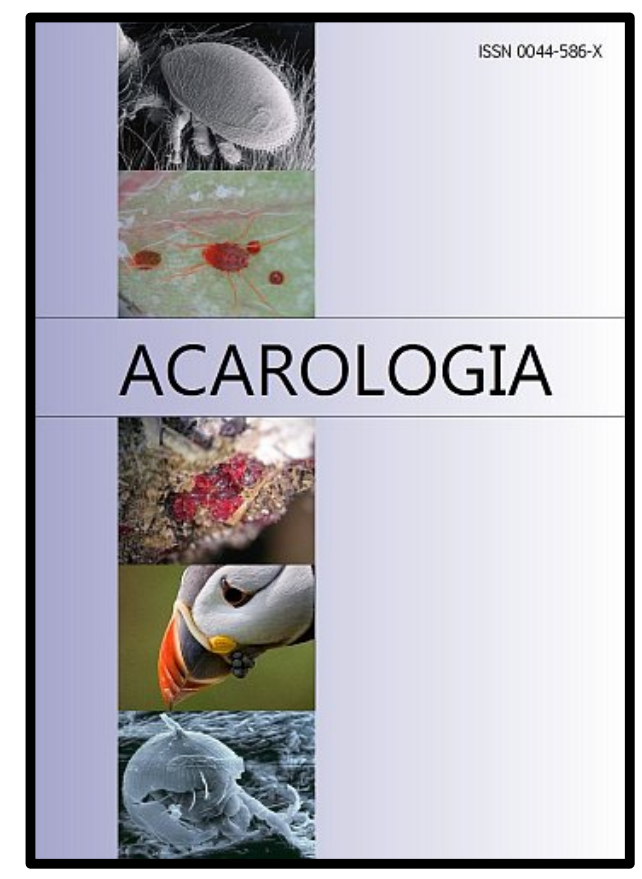

\section{ACAROLOGIA}

A quarterly journal of acarology, since 1959

Publishing on all aspects of the Acari

All information:

http://www1.montpellier.inra.fr/CBGP/acarologia/ acarologia@supagro.inra.fr

\section{OPEN ACCESS}

\section{Acarologia is proudly non-profit, with no page charges and free open access}

Please help us maintain this system by encouraging your institutes to subscribe to the print version of the journal and by sending us your high quality research on the Acari.

Subscriptions: Year 2017 (Volume 57): $380 €$ http://www1.montpellier.inra.fr/CBGP/acarologia/subscribe.php

Previous volumes (2010-2015): $250 € /$ year (4 issues)

Acarologia, CBGP, CS 30016, 34988 MONTFERRIER-sur-LEZ Cedex, France

The digitalization of Acarologia papers prior to 2000 was supported by Agropolis Fondation under the reference ID 1500-024 through the « Investissements d'avenir » programme

(Labex Agro: ANR-10-LABX-0001-01)
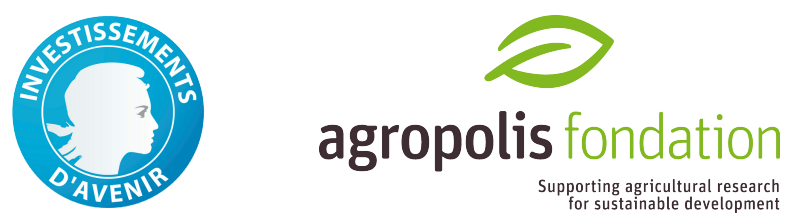

Acarologia is under free license and distributed under the terms of the

Creative Commons-BY-NC-ND which permits unrestricted non-commercial use, distribution, and reproduction in any medium, provided the original author and source are credited. 


\title{
TWO NEW EYELESS MITE SPECIES FROM THE WESTERN PROVINCES OF IRAN: STIGMAEUS LADANAE N. SP. AND STIGMAEUS NASRINAE N. SP.
} (ACARI: STIGMAEIDAE)

\author{
Alireza NAZARI ${ }^{1}$, Mohammad KHANJANI ${ }^{2}$ and Karim KAMALI ${ }^{1}$
}

(Received 29 February 2012; accepted 27 March 2012; published online 22 June 2012)

${ }^{1}$ Department of Entomology, Science and Research Branch, Islamic Azad University, Tehran, Iran. nazariazad@yahoo.com, kamali_k@modarres.ac.ir

${ }^{2}$ Department of Plant Protection, College of Agriculture, Bu-Ali Sina University, Hamedan, Iran. mkhanjani@gmail.com (Corresponding author)

AbStract - Two new species of the genus Stigmaeus, S. ladanae n. sp., collected from soil under apple trees in Abbas Abad Hamedan, Hamedan province and S. nasrinae n. sp., collected from soil under Apera spica-venti (L.) (Poaceae) in Nahavand, Hamedan province, Iran, are described and illustrated.

KEYWORDS - Raphignathoidea; Walnut; first record; predatory mites; Iran

\section{INTRODUCTION}

The members of the family Stigmaeidae are found throughout the world and some of them can feed on the eggs and immature stages of spider mites, eriophyid mites and also immature stages of scale (White and Laing, 1977; Santos and Laing, 1985; Khanjani et al., 2010). They are found abundantly on the trees bark, on or in soil, grass, leaf, mulch, lichen, wood boring beetles, crevices in rock and leaf cavities, and a few of them are parasitic on phlebotomine flies (Dönel and Doğan, 2011). The family Stigmaeidae consists of 32 valid genera and about 500 species so far (Doğan et al., 2011). Fourteen species of the genus Stigmaeus have been reported from Iran, namely: S. alvandis Khanjani and Ueckermann, 2002; S. unicus Kuznezov, 1977; S. elongatus Berlese, 1886; S. candidus Fan and Li, 1993 (= S. mazandaranicus Faraji and Ueckermann, 2006);
S. malekii Haddad et al., 2006; S. pilatus Kuznetzov, 1987; S. shabestariensis Haddad et al., 2010a; S. shendabadiensis Haddad et al., 2010b; S. boshroyehensis, Khanjani et al., 2010; S. marandiensis Bagheri et al., 2011; S. ueckermanni Pahlavan Yali et al., 2011; S. longipilis Canestrini, 1889; S. planus Kuznetzov (Doğan et al., 2012), S sphagneti (Hull, 1918): In this paper S. ladanae $\mathbf{n}$. sp. and S. nasrinae $\mathbf{n}$. sp. are described and illustrated from Iran.

\section{MATERIALS AND METHODS}

Mites were collected from soil beneath Apera spicaventi (L.) (Poaceae) in Nahavand, and soil under apple trees in Abbas Abad, Hamedan, Hamedan province and mounted directly in Hoyer's medium (Krantz and Walter, 2009). The specimens were measured, identified and drawn by means of differential interference contrast microscopy 1000X mag- 
Nazari A. et al.
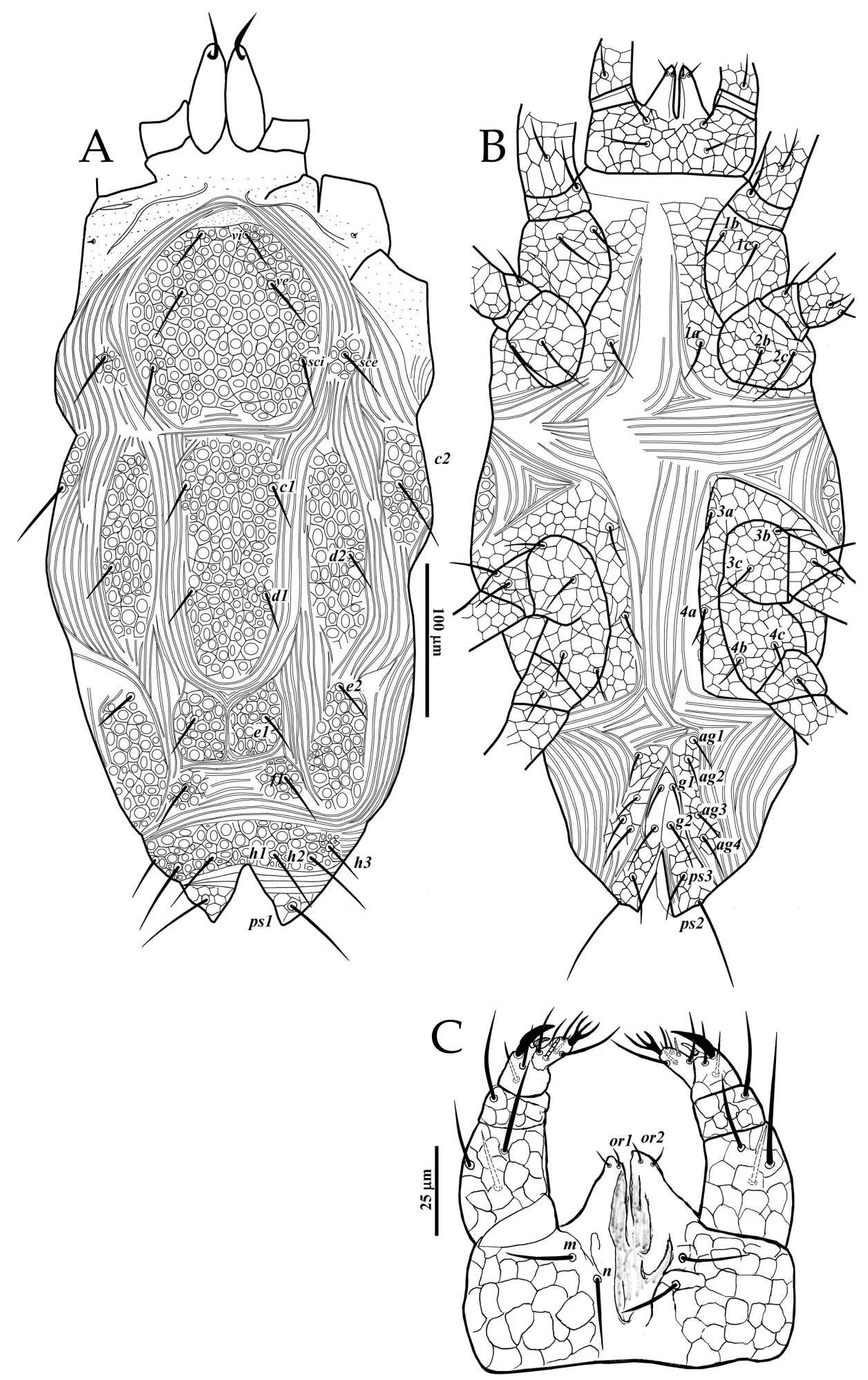

FIGURE 1: Stigmaeus ladanae n. sp. (female): A - Dorsum; B - Venter; C - gnathosoma. 
nification of an Olympus $\mathrm{BX}_{51}$. Body length measurements represent the distance between base of gnathosoma and end of idiosoma; width was measured above coxa III. Setae were measured from the setal base to the tip of the seta; distances between setae were measured between setal bases. Legs measurements are from coxa to pre tarsus.

The terminology and setal notations used in the descriptions of the new species follow those of Kethley (1990). All measurements are given in micrometers $(\mu \mathrm{m})$ and the measurement of the paratypes is followed in brackets.

\section{FAMILy STIGMAEIDAe OUdEMANS, 1931}

Type genus: Stigmaeus Koch, 1836 Stigmaeus Koch, 1836 Type species: Stigmaeus cruentus Koch, 1836

\section{Stigmaeus ladanae n. sp.}

(Figs. 1-2)

Diagnosis - All dorsal, ventral and suranal shields reticulated, dorsum with 14 pairs of setae ( $h_{3}$ present), eyes and post ocular bodies absent, median hysterosomal shield with two setae $\left(c_{1}, d_{1}\right)$, genital setae two pairs, aggenital setae four pairs, genua $5(+1 \kappa)-5-2-2$, propodosomal setae ve/vi $1.26(1.29-1.35)$, ratio $v_{i} / v_{i}-v_{i} 0.85(0.54-0.80)$, $c_{1} / c_{1}-c_{1} 0.52(0.46-0.51) ; c_{1}-c_{1}: d_{1}-d_{1}: e_{1}-e_{1}: f_{1}-f_{1}:$ $0.87(1-1.86)$ : $0.89(0.81-1.60)$ : $0.79(0.81-1.09)$ : 1.0 .

Material examined - Holotype female, collected from soil beneath apple trees, Malus domestica Borkh. (Rosaceae), Hamedan (34 46' $48.13^{\prime \prime} \mathrm{N}$, $48^{\circ} 28^{\prime} 11.46^{\prime \prime} \mathrm{E}$ and altitude $1930 \mathrm{~m}$ a.s.l), Hamedan Province, Iran, 8 June 2011, Alireza Nazari; 6 females paratypes with the same data. The holotype female and 5 paratypes females are deposited as slide-mounted specimens in the Collection of the Acarology Laboratory, University of Bu-Ali Sina, Hamadan, Iran and one paratype female will be deposited in the National Collection of Arachnida, Plant Protection Research, Pretoria, South Africa.

Female $(n=7)-$ Color in life red. Idiosoma oval. Measurements of holotype with measurements of paratypes in parentheses: Length of body (excluding gnathosoma) 420 (419 - 441), (including gnathosoma) 523 (510 - 548); width 206 (206 - 245); length of leg I 240 (218 - 242); leg II 188 (175 - 193); leg III 185 (153 - 190), leg IV 223 (208 - 246).

Dorsum (Fig. 1A) - Prodorsal shield oblong and reticulated; bearing three pairs of setae (vi, ve, sci), eyes and post ocular bodies absent; dorsal hysterosoma with 10 pairs of setae, almost smooth, four pairs of paired and three unpaired shields and surrounded with entire and reticulated (Fig. 1A). Setae $c_{2}$ situated laterally between coxae II-III. Setae ve almost as long as or slightly longer than setae $v i$, setae sce on lateral propodosomal shields, reticulated; lengths of dorsal setae: $v_{1} 23(20-24)$, ve 29 (27 $31), s c_{1} 28(22-29), s c_{2} 30(28-32), c_{1} 25(20-27)$, $c_{2} 41(32-43), d_{1} 19(19-24), d_{2} 21(20-24), e_{1} 22$ $(20-24), e_{2} 21(21-24), f_{1} 30(28-33), h_{1} 32(28-$ 37), $h_{2} 40(37-44)$; distances between dorsal setae: vi-vi $26(25-44)$, ve-ve $50(46-55)$, vi-ve $32(25$ - 34), sci-sci $85(73-88)$, sce-sce $135(131-152)$, ve-sci 47 $(41-50)$, sci-sce $25(18-34), c_{1}-c_{1} 46(43-53), c_{1}-c_{2}$ $73(57-89), c_{2}-c_{2} 191(170-206), c_{1}-d_{1} 59(48-64)$, $d_{1}-d_{1} 47(37-43), d_{1}-d_{2} 49(44-56), d_{1}-e_{1} 68(62-71)$, $d_{1}-e_{2} 51(48-69), d_{2}-e_{2} 73(71-77), d_{2}-d_{2} 128(118-$ $151), e_{1}-e_{1} 42(25-43), e_{2}-e_{2} 94(87-121), e_{1}-e_{2} 33$ (29 - 40), $e_{1}-f_{1} 40(30-42), f_{1}-f_{1} 53(23-53), f_{1}-h_{1} 36$ (32 - 45), $h_{1}-h_{1} 33(31-38), f_{1}-h_{2} 39(36-43), h_{2}-h_{2} 71$ $(64-72), h_{1}-h_{2} 17$ (15 - 21); ratio: vi/vi-vi 0.88 (0.54 $-0.80), c_{1} / c_{1}-c_{1} 0.52(0.46-0.51), d_{1} / d_{1}-d_{1} 0.40(0.51$ - 0.55), $e_{1} / e_{1}-e_{1} 0.5(0.55-0.8), f_{1} / f_{1}-f_{1} 0.52(0.62-$ $1.21), h_{1} / h_{1}-h_{1} 0.96(0.90-0.97), h_{2} / h_{2}-h_{2} 0.56(0.57-$ $0.61), h_{1} / h_{2} 0.80(057-0.84), c_{1}-c_{1}: d_{1}-d_{1}: e_{1}-e_{1}: f_{1}-f_{1}$ : 0.87(1-1.86): 0.89 (0.81 - 1.60): 0.79 (0.81 - 1.09): 1 .

Venter (Fig. 1B) - Coxae I-IV and surrounded shields reticulated, coxisternal shields I-II and IIIIV not fused in mid-line, longitudinal striae; cuticle transversely striate between coxisternal II-III; coxisternal shields I-II and III-IV surrounded by longitudinal striae (Fig. 1B). Length of setae 1a 24 (18 $25), 1 b 22(8-24), 1 c 29(21-32), 2 b 34(25-35)$, 2c $37(28-37), 3 a 23(18-25), 3 b 23(18-24), 3 c 21$ $(17-24), 4 a 21(18-24), 4 b 18(14-19)$ and $4 c 19$ $(14-20)$. Aggenital $\left(a g_{1,-4}\right)$ setae $a g_{1}$ almost as long as $a g_{2,-3}$; and pseudanal seta $p s_{1}$ less than two times longer than seta $p s_{3}$; measurements of setae: setae $a g_{1} 18(14-21), a g_{2} 18(16-20), a g_{3} 22(17-23), a g_{4}$ 


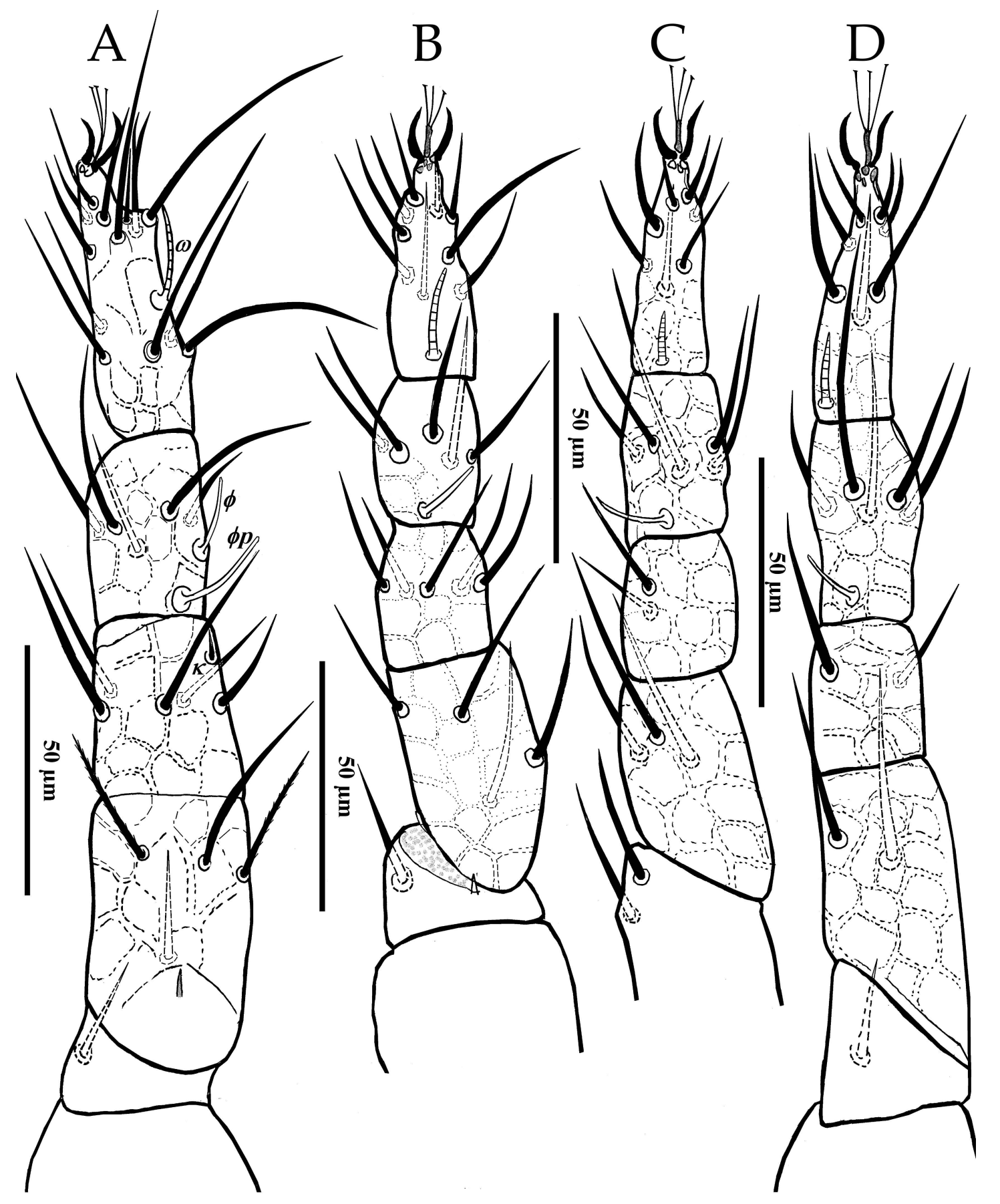

FIGURE 2: Stigmaeus ladanae n. sp. (female): A - leg I; B - leg II; C - leg III; D - leg IV.

$22(19-26), g_{1} 19(16-20), g_{2} 29(19-31), p s_{1} 52$ (36 - 53), $p s_{2} 28(19-28), p s_{3} 44$ (38 - 46). Distances: $a g_{1}{ }^{-}$ $a g_{1} 33(25-33), a g_{2}-a g_{2} 35(33-38), a g_{3}-a g_{3} 49$ (47 53), $a g_{4}-a g_{4} 46(46-61)$.
Gnathosoma (Fig. 1C) - Subcapitulum reticulated and with two pairs of subcapitular setae, $m 23$ $(19-25)$ and $n 18(14-21)$, two pairs of adoral setae, or 7 (4-8), or $29(7-10)$; distances: or $_{1}$-or 17 (5-18), or -or $_{2} 14(11-16), m-m 31(29-36), n-n 23$ 
(23 - 25), or 1 - 25 (24-27), m-n 6 (5 - 7) (Fig. 1C). Chelicerae free $55(50-63)$, movable digit 25(22 27) (Fig. 1C). Palpi five segmented, palp tarsus with four simple setae + one simple eupathidium + one solenidion $(\omega)+$ one tridentate eupathidium, palp tibia with two setae + one well developed claw + one accessory claw, palp genu with one setae and palp femur with three setae.

Legs (Fig. 2) - Legs about half length of body. Leg segments setal formulae as follows: coxae 2 - 2 2 - 2; trochanters 1 - 1 - 2 - 1 ; femora 4 - 4 - 3 - 2, genua $5+1 \kappa-5$ - 2 - 2; tibiae $5+1 \varphi \rho+1 \varphi-5+1 \varphi \rho-5+1 \varphi \rho-$ $5+1 \varphi \rho$; tarsi $13+1 \omega-9+1 \omega-7+1 \omega-7+1 \omega$. Length of solenidia: $\omega I 19$ (16-20), $\omega$ II 17 (14-18), $\omega$ III 10 (7 -12), wIV 8 (6-9).

Male - Unknown.

Remarks - Stigmaeus ladanae n. sp. is closely similar S. shabestariensis Haddad, Lotfollahi and Akbari, 2010 in having:

- setae $h_{3}$

- entire suranal shield,

- reticulated dorsal shields,

- the same legs chaetotaxy.

However, the new species differs in:

- lateral prodorsal shield reticulate in S. ladanae instead of smooth in S. shabestariensis,

- subcapiltulum faintly reticulated instead of faintly punctate,

- dorsal setae smooth instead of serrated,

- lateral zonal shields unique instead of divided in S. shabestariensis,

- base of setae ps1 reticulated instead of smooth in S. shabestariensis,

- ratio $c_{1} / c_{1}-c_{1} 0.52(0.46-0.51)$ and $e_{1} / e_{1}-e_{1}$ $0.5(0.55-0.8)$ in $S$. ladanae opposed to 0.40 $(0.20-0.40)$ and $e_{1} / e_{1}-e_{1} 0.34(0.33-0.34)$ in S. shabestariensis,
- coxal plates I-IV and legs segments reticulated in the new species versus smooth in $S$. shabestariensis,

- aggenital and anal shields reticulated instead of smooth in S. shabestariensis,

- setae $p s_{2}$ two times longer than $p s_{1}$ instead of as long as in S. shabestariensis. Also this species resembles Stigmaeus pulchellus Kuznetsov, 1987 and S. alvandis Khanjani and Ueckermann, 2002 in having all dorsal and ventral shields, and leg segments reticulated, eyes absent, two pairs of median zonal shield;

however it differs from that: aggenital shields reticulated, setae sce shorter than $S$. pulchellus, setae $p s_{1}$ longer than $h_{1}, h_{2}, h_{3}$ instead of as long as in S. pulchellus and also it differs from $S$. alvandis in that:

- the suranal shield entire whereas divided in $S$. alvandis,

- femur IV with two setae opposed to one seta in S. alvandis,

- setae $p s_{1}$ longer than $h_{1}, h_{2}, h_{3}$ instead of as long as in S. alvandis.

Etymology - The new species is named in honor of Mrs. Ladan Mohammadi, wife of senior author, who kindly helped us in mite collection and who is already post student (Agricultural Entomology), Department of Plant Protection, College of Agriculture, Bu-Ali Sina University, Hamedan, Iran.

\section{Stigmaeus nasrinae $n . s p$.}

(Figs. 3-4)

Diagnosis - Prodorsal area with a few reticulations elements centrally, dorsum with 14 pairs of setae ( $h_{3}$ present), eyes and post ocular bodies absent, genital setae two pairs, aggenital setae four pairs, genua 5 - 2 - 0 - 1, palp tarsi with one bifurcate eupathidium, propodosomal setae ve/vi 3.2, ratio vi/vivi $0.59, c_{1} / c_{1}-c_{1} 0.30 ; d_{1} / d_{1}-d_{1} 0.40 ; c_{1}-c_{1}: d_{1}-d_{1}: e_{1}-e_{1}$ : $f_{1}-f_{1}$ 1.06: 0.77: 0.89: 1 .

Material examined - Holotype female, collected from soil under Apera spica-venti (L.) 
(Poaceae) in Nahavand, Hamedan province $\left(31^{\circ} 14^{\prime} \mathrm{N}, 48^{\circ} 23^{\prime} \mathrm{E}\right.$, alitude $1070 \mathrm{~m}$ a.s.l.), Iran, 23 September 2011, by Nasrin Nazari. One female paratype with the same data. The holotype female is deposited as slide-mounted specimens in the Collection of the Acarology Laboratory, University of Bu-Ali Sina, Hamadan, Iran. One female paratype will be deposited in the National Collection of Arachnida, Plant Protection Research, Pretoria, South Africa.

Female $(n=2)-$ Color in life red. Idiosoma oval. Measurements of holotype: Length of body (excluding gnathosoma) 370 (374); width 197 (203); length of leg I 167 (165); leg II 138 (134); leg III 130 (132), leg IV 162 (164).

Dorsum (Fig. 3A) - Prodorsum with a few reticulations elements centrally; with three pairs of setae (vi, ve, sci), eyes and pob absent (Fig. 3A); dorsal hysterosoma covered with longitudinal striae, with nine pairs of setae, almost smooth and four pairs of paired shields (Fig. 3A). Setae $c_{2}$ situated ventrolaterally between coxae II-III. Setae ve 3.2 (2.9) times longer than setae $v i$, seta sce on latral propodosomal area; central hysterosoma stiated, suranal shield divided and smooth and bearing three pairs of setae $\left(h_{1}, h_{2}\right.$ and $\left.h_{3}\right), h_{2}$ almost 1.5 times longer than $h_{1}$ and $h_{3}$ (Fig. 3A); lengths of dorsal setae: vi 15 (17), ve 48 (49), sci 13 (16), sce 24 (21), c 16 (15), c 238 (39), d 15 (15), d 14 (14), e 15 (15), e 14 (15), f 17 (17), $h_{1} 18$ (18), $h_{2} 27$ (26), $h_{3} 20$ (21); distances between dorsal setae: vi-vi 27, ve-ve 35, vi-ve 15 (16), sci-sci 53, sce-sce 124, ve-sci 34 (32), c c -sci 66 (64), $c_{2}$-sce 124 (127), $c_{1}$ - $c_{1}$ 51 (54), $c_{1}-c_{2} 70$ (53), $c_{2}-c_{2} 172$ (175), $c_{1}-d_{1} 54$ (57), $d_{1-}$ $d_{1} 37, d_{1}-d_{2} 49$ (50), $d_{1}-e_{1} 43(44), d_{1}-e_{2} 63$ (65), $d_{2}-e_{2}$ 55 (57), $d_{2}-d_{2} 141$ (143), e e $-e_{1} 41$ (44), e e - e $128, e_{1}-e_{2}$ 43 (47), e e - $f_{1} 28$ (28), $f_{1}-f_{1} 48, f_{1}-h_{1} 47(48), h_{1}-h_{1} 27$, $f_{1}-h_{2} 48$ (46), $h_{2}-h_{2} 40$ (42); ratio: vi/vi-vi 0.59, $c_{1} / c_{1}-c_{1}$ $0.30, d_{1} / d_{1}-d_{1} 0.40, e_{1} / e_{1}-e_{1} 0.36, f_{1} / f_{1}-f_{1} 0.35, h_{1} / h_{1}-$ $h_{1} 0.66, h_{2} / h_{2}-h_{2} 0.67, h_{1} / h_{2} 0.66(0.69), c_{1}-c_{1}: d_{1}-d_{1}$ : $e_{1}-e_{1}: f_{1}-f_{1}$ 1.06: 0.77: 0.89: 1 .

Venter (Fig. 3B) - Coxisternal I-II and III-IV present, smooth. Ventral cuticle transversely striate between coxisternal II-III; coxisternallae I-II and III-IV surrounded by longitudinal striae (Fig. 3B). Length of setae $1 a 20$ (19), $1 b 18$ (17), 1c 25 (26), $2 b$ 39 (38), 2c 25 (29), 3a 21 (18), 3b 21 (23), 3c 17 (16), 4a
18 (16), $4 b 10$ (13) and $4 c 12$ (13). Aggenital $\left(a g_{1,-4}\right)$ setae $a g_{1}$ as long as $a g_{2,-3}$; and genital setae $g_{2}$ longer than $g_{1}$; pseudanal seta $p s_{3}$ almost one half length of setae $p s_{1-2}$; measurements of setae: $a g_{1} 16$ (15), $a g_{2}$ 14 (13), $a g_{3} 21$ (23), $a g_{4} 23$ (24), g 14 (13), g 13 (12), $p s_{1} 19$ (18), $p s_{2}$ 13(15) $p s_{3} 20$ (17). Distances: $a g_{1}-a g_{1}$ 24, $a g_{2}-a g_{2} 32, a g_{3}-a g_{3} 43, a g_{4}-a g_{4} 36$.

Gnathosoma (Figs. 3C, 3D). Subcapitulum with two pairs of subcapitular setae and smooth, $m 19$ (18) and $n 19$ (47), two pairs of adoral setae, or 15 (5), or 10 (9); distances: or -or $_{1}$ 8, or 2 -or 2 12, $m$-m 22, $n-n$ 26, or $1-m 33$ (34), $m-n 7$ (Fig. 3D). Chelicerae free 58 (60), movable digit 27 (27). Palpi five segmented, palp tarsus with five simple setae, one solenidion (w) 5 (6), one bifurcate eupathidium, palp tibia with two setae + one well developed claw + one accessory claw, palp genu with one setae and palp femur with three setae (Fig. 3C).

Legs (Fig. 4) - Legs about half length of body. Setal formulae of leg segments as follows (specialized sensory setae such as solenidia, in parenthesis): coxae 2- 2 - 2 - 2; trochanters 1 - 1 - 2 - 1; femora 4 4 - 3 - 2, genua 5- 2 - 0 - 1; tibiae $5+1 \varphi \rho+1 \varphi-5+1 \varphi \rho$

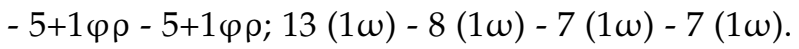

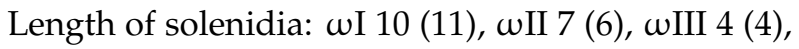
$\omega I V 4(4)$.

Male - Unknown.

Remarks - Stigmaeus nasrinae n. sp. exhibits most features of the $S$. elongatus Berlese (in having a few reticulations elements in median prodorsal area, eyes absent, $h_{3}$ present, palp tibia with three setae. However the new species differs from the latter in: femora I-IV 4-4-3-2 in the new species instead of 6-6-3-2 in S. elongatus, genua 5-2-0-1 instead of 6$5-3-3$ in $S$. elongatus, tarsi II with $8+1 \omega$ oppose to $9+1 \omega$ in $S$. elongates, suranal shield divided instead of entire, aggenital shields with four pairs of setae and two pairs of genital setae instead of five pairs and three pairs respectively in S. elongates. Also closely resembles $S$. caeculus Barilo in having the same legs chaetotaxy dorsal pattern, however differs from the latter by:

- surnal shield with three pairs of setae $\left(h_{1-3}\right)$ in S. nasrinae instead of two pairs in S. caeculus, 

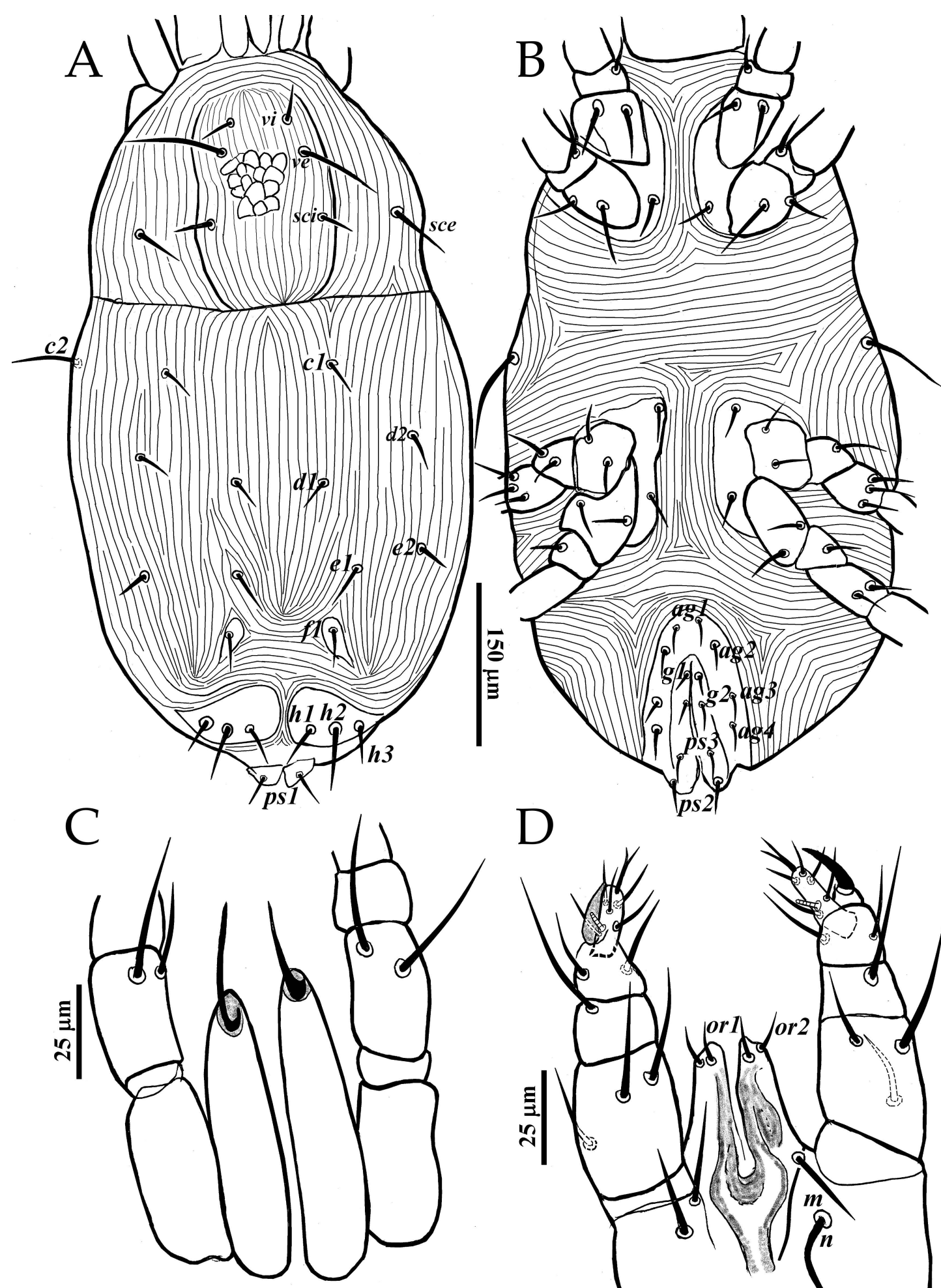

$\mathrm{D}$

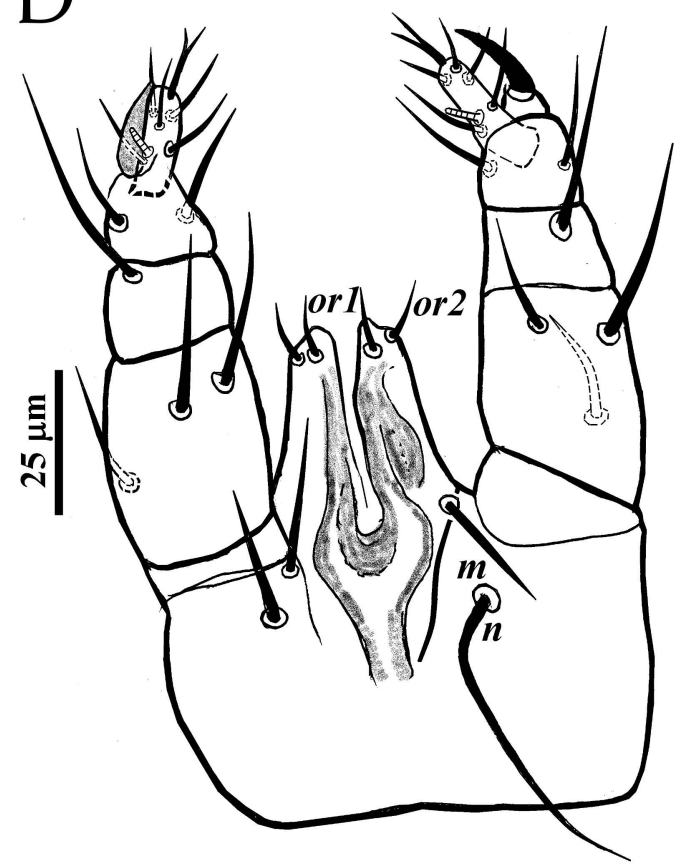

Figure 3: Stigmaeus nasrinae n. sp. (female): A - Dorsum; B - Venter; C - Chelicerae; D - Subcapitulum and palp. 


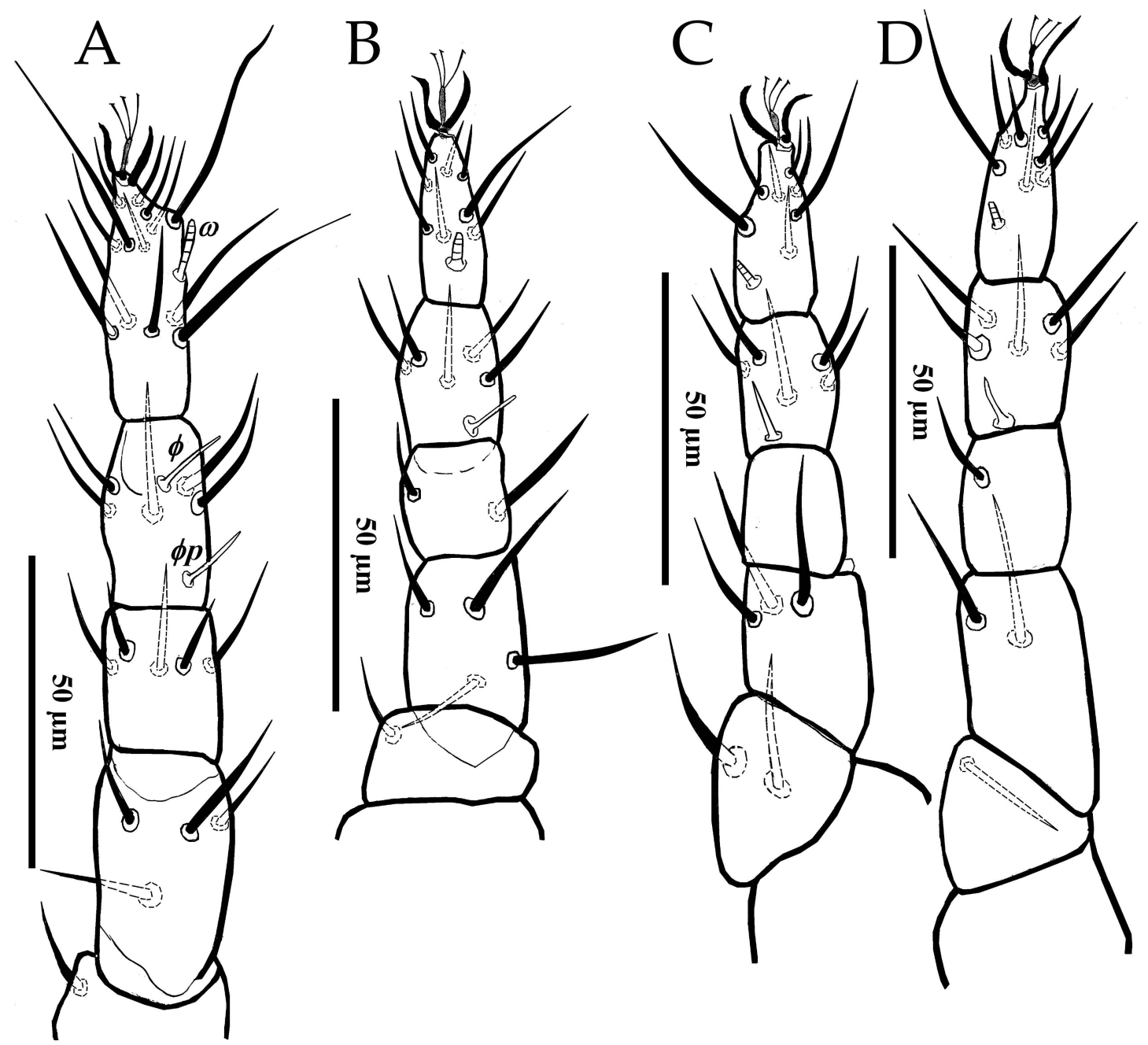

FIGURE 4: Stigmaeus nasrinae n. sp. (female): A - Leg I; B - Leg II; C - Leg III; D - Leg IV.

- seta $f_{1}$ set on the platelet in the new species whereas on the soft integument $S$. caeculus,

- aggenital shields entire instead of divided,

- 27 (26) in the new species, 33 in S. caeculus.

Etymology - The species is named after Mrs. Nasrin Nazari, who kindly assisted senior author in mite collection.

\section{ACKNOWLEDGEMENTS}

The authors wish to thank Prof. Salih Doğan, Erzincan University, Arts and Sciences Faculty, Department of Biology, Erzincan, Turkey for his critical re- view of this manuscript and valuable comment, and suggestions.

\section{REFERENCES}

Bagheri M., Navaei Bonab R., Ueckermann E.A., Ghorbani H., Mehravar A., Saber M. 2011 - Description of a new species of the genus Stigmaeus Koch (Acari: Prostigmata: Stigmaeidae) from east Azarbaijan province, Iran - Syst. Appl. Acarol., 16: 181-186.

Berlese A. 1886 - Acari donnosi alle piante cultivate Podova, 1-31.

Canestrini G. 1889 - Prospetta dell' Acarofouna Italiana, Famiglia dei Tetranychini - Atti Reale Istituto Veneto di Scienze, Lettere ed Arti, 6(7): 591-537. 
Doğan S., Dönel G., Özçelik S. 2011 — A new eyeless mite species of the genus Eustigmaeus Berlese (Acari: Stigmaeidae) from Turkey — Turk. J. Zool., 35: 175-181.

Doğan S., Rahmdeli A., Jalaeian M., Dönel G., Sevsay S. 2012 - Three new records of raphignathoid mites (Acari: Raphignathoidea) from Iran - Turk. J. Zool., (In press).

Dönel G., Doğan S. 2011 - The stigmaeid mites (Acari: Stigmaeidae) of Kelkit Valley (Turkey) - Zootaxa, 2942: 1-56.

Faraji F., Ueckermann E. A. 2006 - A new species of Stigmaeus Koch from Iran (Acari: Stigmaeidae) - Syst. Appl. Acarol., 11: 69-72.

Fan Q.-H., Li L. 1993 - Descriptions of three new species of superfamily Rhaphignathoidea (Acari: Actinedida) — J. Fujian Agric. Univ. (Nat. Sci. Ed.), 22(3): 321-324.

Haddad Irani-Nejad, K., Bagheri M., Khanjani M., Kamali K., Saboori A. 2006 - A new species of Stigmaeus Koch (Acari: Stigmaeidae) from Northwest of Iran Zootaxa, 1354: 57-61.

Haddad Irani-Nejad, P., Lotfollahi K., Akbari A., Bagheri M., Ueckermann E. A. 2010a - Stigmaeus shendabadiensis (Acari: Prostigmata: Stigmaeidae) from Northwest of Iran - Syst. Appl. Acarol., 15: 118-122.

Haddad Irani-Nejad, K., Akbari A., Lotfollahi P., Bagheri M., Ueckermann E. A. 2010b - Stigmaeus shendabadiensis (Acari: Prostigmata: Stigmaeidae) from Northwest of Iran - Mun. Entomol. Zool., 5(2): 369-373.

Khanjani M., Ueckermann E. A. 2002 - The stigmaeid mites of Iran (Acari: Stigmaeidae) - Internat. J. Acarol., 28(4): 317-339. doi:10.1080/01647950208684309

Khanjani M., Izadi H., Asali Fayaz B., Raisi H., Rostami E., Doğan S. 2010 - Stigmaeus boshroyensis sp. nov. (Acari: Stigmaeidae) from eastern Iran, with redescription of Stigmaeus pilatus Kuznezov - Zootaxa, 2727: $34-44$
Kethley J. 1990 - Acarina: Prostigmata (Actinedida) In: Dindal, D. L. (Ed.) Soil biology Guide; John Wiley and Sons, New York. p. 667-756.

Koch C. L. 1836 - Deutschlands Crustaceen, Myriapoden und Arachniden - Regenshurg, 4(9): 1-40.

Krantz G. W., Walter D. E. 2009 - A Manual of Acarology $-3^{\text {rd }}$ edition. Tex Tech. Univ. Mus. Spec. Publ., pp. 807.

Kuznetsov N. N. 1987 - New species of the family Stigmaeidae - Zool. Zhurnal., 54(4): 635-648 [In Russian].

Oudemans A. C. 1931 - Acarologische aanteekeningen CVIII — Entomol. Ber., 8(179): 251-263.

Pahlavan Yali M., Khanjani M., Razmjou J. 2011 - A new stigmaeid mite species from Iran (Acari: Stigmaeidae) and re-description of Stigmaeus longipilis (Canestrini) —Zootaxa., 3089: 60-68.

Santos M. A., Laing J. E. 1985 - Other predaceous mites and spiders 2.2. 1 Stigmaeid Predators - In: Helle W., Sabelis M. W. (Eds). Spider mites their biology natural enemies and Control;World Crop Pests LB. p. 197-203.

White N. D. G., Laing J. E. 1977 - Field observation of Zetzellia mali (Ewing) (Acarina: Stigmaeidae) in southern Ontario apple orchards - Proc. Entomol. Soc. Ont., 108: 23-30.

\section{COPYRIGHT}

$(\mathrm{cc})$ EY-No-ND Nazari A. et al. Acarologia is under free license. This open-access article is distributed under the terms of the Creative Commons-BY-NC-ND which permits unrestricted non-commercial use, distribution, and reproduction in any medium, provided the original author and source are credited. 